Journal of Humanities, Social and Management Sciences (JHSMS)

eISSN: 2788-4791 (online)

https://doi.org/10.47264/idea.jhsms/3.1.7

Vol. 3, No. 1 (January-June 2022), 84-99

https://ideapublishers.org/index.php/jhsms

Research Article

\title{
Prevalence of the Uses and Gratifications Theory amongst the university student consumers of tobacco products in Pakistan
}

\author{
Usman Farooq* \\ Department of Media Studies, The Islamia University of Bahawalpur, Bahawalpur, Pakistan. \\ *Corresponding Author Email: usman.farooq@ prl.com.pk
}

Received: December 18, $2021 \quad$ Accepted: February 11, $2022 \quad$ Published: February 28, 2022

\begin{abstract}
The Uses and Gratification Theory over the years has been found to be the central theory of Communication which aptly describes what exactly people want to do when given the option to use the media. It has been seen that the development of the social media has bestowed a brandnew lease of life expectancy to this old-fashioned and obsolete theory. The reason why this study is being attempted is to explore the existing functions of the Theory of Uses and Gratification among university students who use tobacco. This research has employed Surveys and focus group discussions to elicit information from 1,000 respondents from the two major provinces of Pakistan: Sindh and Punjab, over two (02) year period beginning in 2016. The present quantitative study, while adopting survey as method of research is an effort to examine the views of 1,000 randomly chosen respondents under the age of 25, preferably from educational institutions, including Sindh and Punjab medical colleges. The study confirms the radical upsurge in the present usage of the social media by the masses which has once again renewed a belief in the once considered antiquated Uses and Gratification Theory functions and have in the process provided a plethora of the media uses that in its original form that the traditional media never could.
\end{abstract}

Keywords: Uses and Gratification Theory, smoking, social media, tobacco advertising, media outlets, university students.

\section{How to Cite:}

Farooq, U. (2022). Prevalence of the Uses and Gratifications Theory amongst the university student consumers of tobacco products in Pakistan. Journal of Humanities, Social and Management Sciences (JHSMS), 3(1), 84-99. https://doi.org/10.47264/idea.jhsms/3.1.7

\section{Publisher's Note:}

IDEA PUBLISHERS (IDEA Publications Group) stands neutral with regard to jurisdictional claims in the published maps and institutional affiliations.

Copyright: ( 2022 The Author(s), published by IDEA PUBLISHERS (IDEA Publications Group).

Licensing: This is an Open Access article published under the Creative Commons AttributionNonCommercial 4.0 International License (http://creativecommons.org/licenses/by-nc/4.0/) 


\section{Introduction}

It has been seen that despite laws banning the sale and advertising of tobacco products, tobacco manufacturers have been given the opportunity to reduce the restrictions imposed by the government, thus allowing tobacco advertising to move to the top. respiratory. Powerful tobacco producers are always looking for ways and means to increase strangulation of their population. It is essential for governments to build a strong shield against the publicity of this poison to protect the public from this threat. It has been seen that the study of social networks is of the paramount interest to salespersons, researchers, scholars, strategists, marketers, teachers, students, celebrities, TV channels, advertisers and several other political, economic and socio-political institutions. We must have it in mind that the trust power of modernization and globalization has inevitably compelled several individuals to get online to cope with and carry on with the vigorous demands of the twenty first century technology that we all are surrounded by.

This study hypothesized that peer groups and social pressures are more influential in influencing behaviour than sales promotion in increasing tobacco product use. As of today, daily millions of people feel comfortable in carrying out their activities on the various social network platforms as they can comfortably witness, read, find and share whatever they want, anywhere it may be, anytime that may be at the moment and it may be on any topic which may be of interest to them (Bicen \& Cavus, 2010; Papoola, 2014). The continued internet infiltration continues to expand (more than 3.17 billion internet users are active in the world today) and we find that the social media platforms continue to proliferate at an alarming rate. Whiting and Williams (2013) had quite rightly stated that despite such advanced usage there is little or no understanding amongst our populace of why and how people use social networks. It is estimated that $90 \%$ of smokers are under the age of 18 when they begin their tobacco use in one form or another (Johnston et al., 2020). Therefore, participation of the media becomes essential to increase awareness of the general public against the use of tobacco. Tobacco is also generally believed to have a deleterious impact on the wellbeing of humans which may be either active or passive tobacco exposure to cardiovascular disease (CVD). The exposure to tobacco may lead to other cancerous and respirational diseases (Francis et al., 2015; John et al., 2021).

Scholars like Ruggiero (cited in Gallion, 2010) predicted long before his time that the rise of social media as a decisive element in the world as we now know it would eventually bring about new changes in the economic, political, personal, and social roles and habits of media users. We now see that the original $U \& G$ theory supports this same variety of media consumption. Stafford et al. (cited in Anaeto et al., 2008), has clearly highlighted in his writings to us that the constant appearance of new media and computer technologies have led to an unprecedented rejuvenation amongst the applicability of the Uses \& Gratification theory and have also resulted in a series of a new wave of studies in this regard. We find that amongst the host of users it is the students who are found to be the main users of social networks. The U\&G theory has thus emerged as an ideal theory which can be accurately used to identify and analyse the reasons why the youth use Tobacco products despite the ban on advertising of such products on the social networks (Whiting \& Williams, 2013; Yoo \& Kim, 2013).

It has also been proved that the application of the Uses \& Gratification theory in our social media studies cannot be underestimated as despite the differences we stumble upon we find 
that there are considerable similarities which exist between new forms of mass media which are relative to the old media as well. However, it has to be accepted that unlike traditional media that used to give users only limited options, these new media present new options and thus the theory when applied in true letter and spirit will help explain the dilemma of U\&G (Gallion, 2010; Matei, 2010). As a result of their being limited studies to accurately substantiate the $U \& G$ theory in social media relationships this research is being undertaken to apply the U\&G theory to help understand better if students are using the social media at their disposal to educate themselves about the harmful effects of tobacco. and how and why do they justify the rewards they have achieved. Therefore, this work seeks to:

- Find out if it is incorrect to expect that peer businesses and social pressures are extra influential than income promoting with inside the growth of Tobacco products.

- Investigate whether or not college students who use tobacco use social networks.

- Observe the desire of social networks amongst college students who use tobacco.

- Determine the pertinency of U\&G Theory vis-à-vis engagement of social media networks to justify intake of tobacco products for themselves by university students.

\subsection{Use of tobacco}

McMaster and Lee (2014) through a research study recommended that the textual analysis inscribed on the packages that are distributed in Australian and Canadian societies had a positive impact on smokers. The study also suggested that the health-related text appeal might be more effective. A study conducted by the WHO (2007) revealed that, despite serious threats to physical and psychological health, the tendency to smoke was increasing among adults in European countries. Gallopel-Morvan et al. (2011) stated that each year more than half a million deaths were reported in these countries due to smoking. The study also goes into more detail on the problems posed by smoking and suggests that smoking is now a major problem for most countries, especially among its young people. The study also found that the UK was the worst-hit country. In his study, Rothschild (1999) described procedures and methods that, if adopted, could help people take these steps.

\subsubsection{Advertising}

Strahan et al. (2002) and Whittingham et al. (2008) suggested that intense antismoking advertising on social media was imperative to reduce the smoking phenomenon. The drive should promise a healthier life and future prosperity. This paid campaign should raise awareness of the dangers related to tobacco use. Visible pictorial warnings should also be displayed on the cigarette package and such antismoking appeals can be used to prevent the prevalence of smoking behaviour in people.

\subsubsection{Cognitive dissonance}

The studies of Hupp et al. (2008) and Gröppel-Klein (2014) showed that the emotions of disgust, sadness, fear, and anger are the main overlapping emotions and, at a broader level, have negative consequences among smokers. Biner et al. (2004) have produced a lot of literature on the subject of emotions, and Marzillier (2004) showed through a study that fear and disgust can be abused as a result of smokers' smoking cessation behaviour through advertisements. 


\subsubsection{Psychological addiction}

The studies of Hagger et al. (2013), Yoo and Kim (2013) and Vangeli et al. (2011) have comprehensively concluded that physical and psychological dependence on tobacco products leads to self-control problems, providing insight into why quitting attempts generally fail. This is the very reason why smokers in our society do not easily quit smoking. However, Loewenstein (1996) undeniably argues that tobacco products are one of the types of products associated with visceral effects, and smokers feel that they eliminate these feelings by consuming more of the same product, and generally place these users constrained from deeply consuming the same.

\subsection{Use of social media}

Kaplan and Haenlein (2010) have provided come up with what can be termed as a comprehensive definition of the social media which captures the essence of the term beautifully, they imply that what we see today in terms of the social media is "a group of Internet applications that are based on ideological and technological underpinnings which thereby allow the unhindered creation and free exchange of messages". Douglas (cited in Papoola, 2014) has also given the social media the meaning of being any digital medium that has the ability to be used to freely exchange ideas, status, photos, news, opinions, messages, information, music, ring tones, melodies and videos with the fellow cybernetic community. Understandably it is for this very reason that the social networks seem to rely heavily on mobile apps and websites built for the very purpose of social interaction and that these users to generate, say and communicate knowledge about others or themselves. Similarly, it has been seen that when some people use these technologies for educational purposes they mostly interact and share information online. The commonest social networks which are in abundance in our midst include Instagram, Facebook, Twitter, LinkedIn, TikTok, Pinterest, Reddit, YouTube, and WhatsApp, blogs, Google+, Snapchat, QQ, Douyin, Sina Weibo, Telegram, Kuaishou and Flikr (Lewis, 2009; Osatuyi, 2013; Whiting \& Williams, 2013).

\subsubsection{Social interaction}

We find that the process of social interaction or assimilation amongst social media users (Asemah, 2009) is a prime reason for resorting to the heavy usage of the social media in our midst today. A crucial purpose of the media is to be a setting for unhindered public debate thus encouraging freedom of speech. With the heavy online presence on social networks of users on the platforms of Instagram, Facebook, Twitter, WhatsApp and Forums Online which enables the users not only to take part in communication but also to work together concurrently on various topics of mutual interest. Whiting and Williams (2013) after carrying out diverse studies in the field of communication studies reveals that $88 \%$ respondents' use social media is primarily to interact \& communicate with their spouses, family, old and new friends. Papoola (2014) reached also reached a similar conclusion on the culmination of his research.

\subsubsection{Waste of time}

Many people just resort to the use media to relieve stress or have fun. Indeed, $76 \%$ respondents who were part of Whiting and Williams (2013) and Edegoh et al. (2013) studies were found to engaged in the use of Facebook when they had time during work or in a travelling mode may 
it be train, bus railway, airplane etc. Even when students were inside classroom waiting for the class to start, they would go online. Asemah (2009) adds that people who in the past used to read books to unwind and entertain themselves are now seen using social media thus not making full use of the faculties of their brains, restricting themselves to what all is available in the cyber world.

\subsubsection{Entertainment}

It has been seen that entertainment is now considered to be the prime function of mass media as it has been seen that people often like to be entertained rather than educated. It has been proved that the ever-emerging trends we are seeing in the social media around us has preserved the component of entertainment as the single most essential purpose, and it has been discovered that the majority of respondents use social media exclusively to meet their demands for relaxation, entertainment and enjoyment. Gallion (2010). Whiting and Williams (2013) have also expounded that during their research they saw that $64 \%$ of their respondents indulging in the extensive use of mass media in order to pass their time by merely going through the items which are displayed on their fancy devices, are playing games, reading and posting amusing and entertaining comments, and watching the stuff on their devices that they believe can provide them with entertainment.

\subsubsection{Sharing and seeking of information}

The advancement in the social media now makes it much easier for a person to lay his hands on information he was not privy to earlier. Despite the ease of the disbursement, we find in information research has shown that students do not move beyond the basic information available to them on the social media. It has been unfortunately seen that nearly all Facebook users are highly gratified with the quantity and quality of political, economic, and civic information they receive over the Facebook pages they surf (Park \& Park, 2018; Gallion, 2010). Thus, the U\&G theory allows individuals to use precise media for their diverse needs (depopulation), 80\% of respondents to Whiting and Williams (2013) find information about Communication, Collaboration, Paid Advertising, Deals, Sales, Products, Brand Monitoring, Companies, Entertainment, Birthdays, Parties, Media Sharing and use the social media to learn how to make things.

\subsubsection{Socialization}

Gallion (2010) has explicitly stated socialization to be the single greatest essential element of the U\&G theory in media studies. The need to be appreciated which leads to our socialization in the shape of meeting new friends and subsequently then achieve a relationship by staying in touch is a dire product of our socialization needs. According to Edegoh et al. (2013)'s study on Facebook and Relationship Management, the majority of the survey respondents were found to be continually utilising their Facebook accounts in an effort to meet new people and reconnect old acquaintances.

\subsubsection{Self-expression}

The feeling which Robert Maslow has very aptly covered in his pyramid of needs hierarchy is the need to express oneself in society. It has been found that there are people who like to remain 
quiet and aloof while others are seen to be fond of making an impression by leaving their inedible mark on the social media. People who previously did not have access to social media or could not afford to acquire expensive columns in newspapers and magazines have now resorted to Tik Tok-like social media platforms as a result of the fast rise of social networking sites and we find pseudo intellectuals very often on our social media platforms churning out advice in the shape of analysts, hosts, religious leaders, pundits, human rights activists and professionals of everything under the sky. Whiting and Williams (2013) also discovered that an enormous proportion of the users of the social media who were $56 \%$ of their respondents were involved in the usage of the media not to openly express their feelings, opinions and judgements by just going to the relevant social media platform and after going there liking pages, posts, snaps, photos and comments were showing their gay abandon in the blind pursuit of the social media.

\subsubsection{Education}

It should ideally be amongst the most important functions of the media however we see that unfortunately the function to educate and train people is not as wholeheartedly being accepted by the general public as would have been desired by the social media pundits. Asemah (2009) emphasized that communities, societies, individuals, families, groups all should depend on the media for their education, understanding, learning purposes, promotion, and self-development. Users become more engaged as a result of the U\&G theory by doing things on their own. Most respondents ranging from Eke and Odoh (2014) and Papoola (2014) have reemphasized the prolific use of the social media for solely academic purposes. However, it is seen that the vibrant presence of social media search engines nowadays e.g., Google and Wiki give an opportunity to people to keep on looking for educational writeups in order to strengthen their online learning experiences.

\subsubsection{Surveillance}

McQuail et al. (cited in Asemah, 2009) in their research were of the opinion based on their results that people were often found to be using the social media for the purpose of spying, snooping, or eavesdropping just to see what was happening inside and outside their domain. Thus, we are finding more and more people getting involved in the process of hacking bringing IT security to light. It transpired that there were $32 \%$ respondents who were accepted the fact that they were more often than not involved in the use of the social media to spy on and monitor what others are doing. We find that the mainstream media cannot just cover everything that is being seen around us because of the vast spaces involved, fear of being caught and the stifling presence of censorship. We often see that the people who are carrying digital cameras and cell phones, happen to be at the site of any incident which may garner public interest can now upload photos and videos to the relevant social media platform in a blink of an eye which is then subsequently available to be seen by millions of people around the globe. Therefore, the idea of civic or guerrilla journalism is inspired by this surveillance function of the social media (Papoola, 2014).

\subsubsection{Anti-smoking media campaigns}

Boes et al. (2015) and Kan (2007) also concluded that measures such as smoking bans by institutions were also helpful in controlling the behaviour of people who may intend to avoid 
or quit the smoking altogether. Marti and Sindelar (2015) also believed that the availability of small cigarette packs in the market compared to the prices of large cigarette packs, contrary to the facts, were encouraging smoking behaviour (Cornuz et al., 2006; Hoogendoorn et al., 2010). Witte and Allen (2000) found that awareness among smokers helped them adopt a preventive behaviour or resist the temptation to succumb to the habit in their early years. Thus, Gharlipour et al. (2015) and Peters et al. (2013) revealed that it was imperative that the antismoking media campaigns advocate a moderate model of fear coupled with a high degree of self-efficacy.

\subsubsection{Communication}

Social networks offer users the opportunity and freedom to individuals to communicate with each other. Whiting and Williams (2013) during the course of their exhaustive research had arrived to the conclusion that $56 \%$ of the respondents they reached out to are prolific in the use of the social media to discuss ideas, interact, chat, gossip and deliberate with friends on what they have been through in life in terms of their experiences as well as share thoughts on what they may happen to see or read while surfing on the social media. It is important to note that unlike our conventional media where we see that the process of feedback is considerably delayed or altogether missing typically it is not guaranteed, the social media contributors enjoy the privilege of immediate feedback.

\section{Theory of Uses and Gratifications}

It was Katz, Blumler, and Gurevich who are credited with the initial work carried out on the theory of use and satisfaction in 1974. McQuail (2010) however has given this theory a historical perspective which dates back to the early 1940s once researchers initially began probing into how and why was it that people listen to popular radio stations and kept themselves busy in reading the newspapers of their choice. Thus, this was how this theory initially emerged as a rejoinder to the dire need of social media researchers to try and as accurately as possible explain why was it that certain individuals employ certain means of the social media and derive gratification as per their own peculiar and what in fact are the benefits that they derive. Communication researchers apply the U\&G theory in an effort to study, explain, and correctly present why is it that people use only specific media and what are the advantages or gratification that they derive because of this consumption. It can be confidently asserted that this theory assumes that more often than not people make use of media for reasons which are truly only known to them thus they seek various pleasures which they fancy in their minds (Gallion, 2010; Wimmer \& Dominick, 2014; Asemah, 2009).

It has been seen that in our mindset the tremendous rise in the use of social media technology is abruptly changing the way people were earlier employing in the use of mainstream media. Thus, when we compare the people who are presently using social network sites and other computerized forms of communications which are in vogue, we find that they are very different from the earlier mainstream media audiences whose consumption was based on a specific media content ( $\mathrm{Li}, 2005)$. These days we find that the social media audience has the uncanny advantage of freedom on the social media networks to get information in the area of interest of their particular liking and this also provides an opportunity for them to actively explore enlightening and diverse messages from all over the planet. It has been noticed that with the passage of time the modern media technologies which have been introduced recently have not 
only managed to drastically change how this information is collected, collated and subsequently disseminated, but the balance of the relationship which exists between the media and the audiences has been altered.

Li (2005) while investigating about this in his study, came to the conclusion that people use social media networks to meet majority of their needs, such as physiological needs, safety needs, love relationship, belonging needs, esteem needs, self-actualization needs, cognitive needs, emotional needs, average attractiveness needs, personal integration needs, social integration needs, and stress relief needs, to name a few. It is to this end that we observe that social media networks have become an enormously rich arena for all study, demonstrating very clearly the direct application of the U\&G Theory to users of the social media apparatus (Matei et al., 2010).

In reviewing the associated findings, the researchers combined and then thoroughly investigated the works of Asemah (2009), Gallion (2010) \& Whiting and Williams (2013). After this process they were of the view that most people use social networks to interact, kill time, entertain themselves, seek and share information, socialize, express themselves, educate themselves, monitor each other and communicate.

\section{Research design}

This research is basically quantitative in nature by employing survey as a research method with 1000 respondents from two major provinces of Pakistan including Sindh and Punjab. The researchers chose the quantitative method due to multiple factors, mainly because the survey was the most appropriate model to assess the opinion of the respondents, especially those under 25 years of age. The present investigation was carried out with the participation of 1000 respondents taken as a sample for the study and only those respondents who were tobacco users and, of the total number of respondents, about 500 respondents formed the intervention group chosen from random sampling.

Four medical schools, the DOW Medical College, Karachi, the Sindh Medical College, Karachi, the Nishtar Medical College, Multan, and the Quaid-e-Azam Medical College Bahawalpur were randomly chosen from the selected academic institutions, which were: the Lahore Medical College, Lahore, the Nishter Medical College, Multan, the Sindh Medical College, Karachi, the Quaid-e-Azam Medical College Bahawalpur, and the DOW Medical College, Karachi, to collect an authentic data from the students. In addition, the researchers selected six faculties from the Karachi University, i.e., Geography, Social Welfare, Islam, English, Media, and Statistics. Among them, three departments were randomly selected as: Department of Geography, Department of Computer Engineering, and Department of English. Procedurally, the questionnaires were distributed to the respondents using convenience sampling method.

\subsection{Research techniques}

The underlying studies is quantitative in nature using survey as a studies approach with a thousand respondents from principal provinces of Pakistan such as Sindh and Punjab. The researchers selected the researchers implemented a sequential explanatory combined approach layout to acquire and examine the data on hand. Survey questionnaires and awareness 
institution discussions have been used to elicit respondents` evaluations and perceptions in their tobacco use and satisfaction. The SPSS statistical package for social sciences (SPSS) has been utilised to help the researcher comprehend the replies of the participants via the application of narrative statistics and theme assessment.

\subsection{Selection process}

It was made sure that feedback forms were assigned to all the respondents of the study. After the exhaustive assessment of the feedback forms, we had college students who possessed excessive know-how on the use of social networks and who were also consumers of tobacco products that were selected.

\section{Analysis and discussion}

\subsection{Survey outcome}

Paper questionnaires were distributed to 1,000 respondents in the first phase. These participants were both addicted to tobacco and were also proficient in the use of the social media. Men made up $79 \%$ of the sample $(n=88)$, while women made up $27 \%(n=23)$. A total of 71.2 percent of the participants were between the ages of 25 and 31; 12.6 percent were between the ages of 32 and 38; and 2.7 percent were under the age of 18 . During the course of this study, 11 individuals were embarrassed to share their ages with the researchers because they were afraid of being judged. Many (44.1 percent) were single, 34.2 percent were married, and 18.9 percent were divorced/separated, according to the survey.

\subsection{Focus group outcome}

After the first phase in the second phase of the study it was then decided to gather the students who were involved in the frequent use tobacco products were invited to a very detailed focus group discussion held on campus. The idea was to try to understand why the students who were adequately aware of the ill effects of this menace still were involved in the use of cigarettes and what on earth were the benefits/rewards they received in return. Out of the 25 participants in the focus group discussion, 17 were male and 8 were female. It was mandatory for all the of them to be smokers and to be approximately in the age group of 18 and 24, this was with the sole exception of three participants who were between the ages of 24 and 45 . During the process of this phase of the research the researchers opted for the use of open-ended questions. After a lengthy conversation with the participants, the data was then video recorded with their consent and preserved for future generations.

Table- 1 shows that out of the 1000 respondents we interviewed a great majority $996(99.6 \%)$ were users of the social media while a mere $4(0.4 \%)$ did not have any use of the social media in their lives.

Table-1: Do you resort to the use social media in your daily life?

\begin{tabular}{|lcc|}
\hline & Frequency & Percent \\
\hline No & 4 & 0.4 \\
Yes & 996 & 99.6 \\
Total & 1000 & 100.0 \\
\hline
\end{tabular}




\subsection{Participants reliance on social networks}

Social networks have become as an important aspect of many students' life in a short period of time. People who utilised social media to make new acquaintances, interact, mingle and learn new things. Facebook, WhatsApp, and Twitter were the most frequently used social media platforms among the several others.

The table- 2 shows that 95 percent of the population use Facebook followed by WhatsApp with 94,6 percent users as the most popular form of social media tool in use.

Table-2: If given an option what would be your preferred mode of social media?

\begin{tabular}{|lcc|}
\hline Social networks & Frequency & Percent \\
\hline LinkedIn & 12 & 2.4 \\
Skype & 49 & 9.8 \\
Blog & 67 & 13.4 \\
Twitter & 245 & 49.0 \\
Instagram & 261 & 52.2 \\
YouTube & 389 & 77.8 \\
Google & 469 & 93.8 \\
WhatsApp & 473 & 94.6 \\
Facebook & 475 & 95.0 \\
Others & 24 & 4.8 \\
\hline
\end{tabular}

Table-3 shows that unfortunately, just $38.0 \%$ of those polled said they acquire their news or information from social media. Most respondents were utilising social media mainly for amusement purposes, as shown by this study.

Table-3: Is social media in your life a source of news or information?

\begin{tabular}{|lcc|}
\hline & Frequency & Percent \\
\hline No & 618 & 61.3 \\
Yes & 380 & 38.0 \\
No response & 2 & 0.2 \\
Total & 1000 & 100.0 \\
\hline
\end{tabular}

Table-4 reveals that almost half of the population (44.2\%), a small minority (1.8\%), and nearly two-thirds $(64.6 \%)$, believe that the media can play a dominant role in forming public awareness of the dangers of smoking; 24.6 percent of the respondents believe that their parents can play an important role in educating their children about the dangers of smoking; and 10.8 percent believe that religious scholars can play a significant role.

Table-4: Who can make a difference in the understanding and perils on the prevailing massive use of tobacco amongst students.

\begin{tabular}{|l|c|c|l|l|l|c|c|}
\hline \multirow{2}{*}{ Group } & Option & $\begin{array}{l}\text { Mass } \\
\text { Media }\end{array}$ & $\begin{array}{l}\text { Religious } \\
\text { Lectures }\end{array}$ & Parents & Teacher & Peers & Total \\
\hline \multirow{2}{*}{ Control } & $f$ & 209 & 12 & 124 & 60 & 95 & 500 \\
\cline { 2 - 8 } & $\%$ & $20.9 \%$ & $1.2 \%$ & $12.4 \%$ & $6.0 \%$ & $9.5 \%$ & $50.0 \%$ \\
\hline \multirow{2}{*}{ Intervention } & $f$ & 233 & 6 & 122 & 48 & 91 & 500 \\
\cline { 2 - 8 } & $\%$ & $23.3 \%$ & $0.6 \%$ & $12.2 \%$ & $4.8 \%$ & $9.1 \%$ & $50.0 \%$ \\
\hline \multirow{2}{*}{ Total } & $f$ & 442 & 18 & 246 & 108 & 186 & 1000 \\
\cline { 2 - 8 } & $\%$ & $44.2 \%$ & $1.8 \%$ & $24.6 \%$ & $10.8 \%$ & $18.6 \%$ & $100.0 \%$ \\
\hline
\end{tabular}


According to table 5, about $69 \%$ of respondents said they were willing to quit smoking because it was harmful to their health. Only $9.8 \%$ of the population wants to quit smoking. Because such social evil is contrary to the spirit and teachings of religion. Only $6.6 \%$ of the respondents said that they had other reasons, and only $7.6 \%$ of those who said that all of the above reasons led to quitting smoking.

Table-5: Motivating factor behind your decision to quit tobacco?

\begin{tabular}{|l|c|c|c|c|c|c|}
\hline \multirow{2}{*}{ Group } & Option & $\begin{array}{l}\text { For improving } \\
\text { my Health }\end{array}$ & $\begin{array}{l}\text { It is against the } \\
\text { tenants of my faith }\end{array}$ & $\begin{array}{l}\text { Any other } \\
\text { reason }\end{array}$ & $\begin{array}{l}\text { All of the } \\
\text { above }\end{array}$ & Total \\
\hline \multirow{2}{*}{ Control } & $f$ & 337 & 51 & 36 & 76 & 500 \\
\cline { 2 - 7 } & $\%$ & $33.7 \%$ & $5.1 \%$ & $3.6 \%$ & $7.6 \%$ & $50.0 \%$ \\
\hline \multirow{2}{*}{ Intervention } & $f$ & 353 & 47 & 30 & 70 & 500 \\
\cline { 2 - 7 } & $\%$ & $35.3 \%$ & $4.7 \%$ & $3.0 \%$ & $7.0 \%$ & $50.0 \%$ \\
\hline \multirow{2}{*}{ Total } & $f$ & 690 & 98 & 66 & 146 & 1000 \\
\cline { 2 - 7 } & $\%$ & $69.0 \%$ & $9.8 \%$ & $6.6 \%$ & $14.6 \%$ & $100.0 \%$ \\
\hline
\end{tabular}

Table- 6 shows that smoking cessation campaigns can be more effective through television advertising. $30.1 \%$ believe that social media advertising can play a more active role in educating people to quit smoking. $42.3 \%$ of the public favoured placing ads on various media platforms, which they consider the most effective channel for anti-smoking campaigns. As a result, $4.9 \%$ believe that warning pictures on cigarette packs can be an influential tool and $2.3 \%$ believe that information walks can play an important role in increasing the effectiveness of tobacco campaigns.

Table-6: Most effective medium to spread awareness against the consumption of tobacco?

\begin{tabular}{|l|c|c|c|c|c|c|c|}
\hline \multirow{2}{*}{ Group } & Option & $\begin{array}{l}\text { Through } \\
\text { T.V } \\
\text { Plays }\end{array}$ & $\begin{array}{l}\text { Social } \\
\text { Service } \\
\text { Advertising }\end{array}$ & $\begin{array}{l}\text { Through } \\
\text { commercial } \\
\text { Ads }\end{array}$ & $\begin{array}{l}\text { Pictorial } \\
\text { Warnings } \\
\text { on packs }\end{array}$ & $\begin{array}{l}\text { Walk and } \\
\text { seminars }\end{array}$ & Total \\
\hline \multirow{2}{*}{ Control } & $f$ & 98 & 157 & 198 & 34 & 13 & 500 \\
\cline { 2 - 8 } & $\%$ & $9.8 \%$ & $15.7 \%$ & $19.8 \%$ & $3.4 \%$ & $1.3 \%$ & $50.0 \%$ \\
\hline \multirow{2}{*}{ Intervention } & $f$ & 106 & 144 & 225 & 15 & 10 & 500 \\
\cline { 2 - 8 } & $\%$ & $10.6 \%$ & $14.4 \%$ & $22.5 \%$ & $1.5 \%$ & $1.0 \%$ & $50.0 \%$ \\
\hline \multirow{2}{*}{ Total } & $f$ & 204 & 301 & 423 & 49 & 23 & 1000 \\
\cline { 2 - 8 } & $\%$ & $20.4 \%$ & $30.1 \%$ & $42.3 \%$ & $4.9 \%$ & $2.3 \%$ & $100.0 \%$ \\
\hline
\end{tabular}

\section{Discussion and findings}

Our country, Pakistan is faced with a very serious public health catastrophe especially amongst the students at universities because of the readily available tobacco products being sold all over the country. This inevitably affects the development of the human capital of the nation as well as the national exchequer. Regrettably, our politicians whom we so lovingly elect are oblivious to the seriousness of this predicament being faced by the masses. Convincing evidence shows that insidious tobacco advertising has a large part to play in the encouraging these behaviours in non-smokers especially adolescents. Over the ages it can be seen that advertising has always been an important decision-making aspect, especially among the youth who are generally more impressionable. Partial prohibitions, such as a ban on television advertising, have had little impact on sales throughout the years. Partial advertising prohibitions have been shown to be readily replaced by other media or promotional approaches. In these partial ban scenarios, tobacco businesses and advertising agencies have showed considerable ingenuity. 
The U\&G Theory has been shown to be relevant, legitimate, and significant in the social media usage of smokers in this article. Understanding why individuals use social media, what advantages they get, and why they favour some social networking sites over others may be gained by using the U\&G Theory in social media research. According to the survey and focus group discussions, 98.2 percent of the participants in this research are active social media users. According to Papoola (2014), the vast majority of students in higher education use social media to some extent. Educators at higher education institutions may benefit from this change by considering how to use social media to assist students overcome their addiction to tobacco products. This research has led to confirmation of the significance and soundness of the Users $\&$ Gratification Theory with respect to the emerging social media. In addition, it was found that majority of respondents utilised social networking sites rather than news or informationpropagating sites. Among the participants, Facebook, Twitter, and WhatsApp were determined to be the most popular forms of social networking.

We found out through the course of this research that Omekwu et al. (2014) and Papoola (2014). Both were not far from the truth when they identified seven reasons why students who were involved in the consumption of tobacco products eventually used social media for the purpose of uses and gratification which are: (a) making friends from other countries by connecting anytime, (b) news sharing thus making an effort to educate oneself, (c) research that is the process of getting to know more and more, (d) the ability to communicate one's thoughts and ideas in a public forum, such as a blog or other online forum, (e) maintaining a connection that is in other words build a relationship, (f) collaboration and last but not the least (g) communication is a means of getting to know other people.

This paper is an effort on part of the researcher to make a valuable contribution in two very simple ways: firstly, findings of the study shows that the Users and Gratification Theory is very much valid and authentic in this time and age thus it's applicability to the students' as far as the use of social media networks remains constant and future researchers should therefore remain cognizant of its relevance (Whiting \& Williams, 2013). Again, secondly, we find that there are a few respondents who have used the social media platform but unfortunately, they are in a minority.

All media formats, including electronic, print and social media, provide the most attractive tobacco-related second-hand advertising to the general public and smokers. However, the majority of the population, with an average of $50 \%$, believed that TV talk shows could have a greater impact in this regard.

The youngsters were more likely to use tobacco, especially cigarettes, while at home, and although they tended to be easier to use due to commercials through electronic media, most of the public liked to smoke because of inspirations, thanks to their friends. The research brought out that the consumers were not satisfied with seeing tobacco-related advertisements on national and international media channels that showed the heroic moves of the models featured in the commercials.

This study may also broaden the horizons of the phenomenon under discussion and may also provide researchers with future avenues to explore more pathways of collective and individual well-being in society. 


\section{Conclusion}

To conclude we reiterate that this study has made an endeavour to explore the U\&G's theory amongst the tobacco consuming youth and made inroads to investigate the social media against the prolific use of tobacco in educational institutions of Pakistan. We find that over a period the use of tobacco is now once again becoming common amongst students. We have to admit that the social media has a vast reach over the students especially this should be put to good use. Pakistan faces a serious public health disaster due to the outbreak of the tobacco epidemic. This will obviously affect the country's human development and national economy. Unfortunately, politicians and politicians don't seem to realize the seriousness of the problem. Ads for tobacco products have been shown in several studies to be a significant factor in nonsmokers' desire to smoke. When it comes to young people, advertising has always been a significant factor in their decision-making process. Partial bans on advertising, such as a ban on television commercials, have little impact on sales, according to studies However, there is evidence that a prohibition on certain advertising just leads to the replacement of other forms or techniques of promotion. Because of the partial prohibition, tobacco manufacturers and advertising firms have had to become creative.

It is hoped that once this research is made public it will lead to a positive contribution on firstly the literature, and secondly theoretical foundations of existing mass communication studies. Over the course of this study, it was discovered that our good old usage and satisfaction theories are still relevant to the present-day social media research. The respondents who were contacted in this study were primarily users of tobacco and were proficient in their use of the social media. Only a small percentage of those who took the survey utilised social media to keep up with current events and sharpen their analytical skills. Present research study also suggests that researchers need to delve deeper into the realm of social media to explore the theory of media information utility in more details especially when the young are in the process of using social media sites. Facebook, WhatsApp, and YouTube are the preferred mode of social networking thus These social media networks have the potential to make any message more impactful. Finally, I'd want to stress that U\&G theory allows people to pick the media platform that best "satisfies" their "needs.", what however remains is that those needs should be productive in nature and lead to better human beings who add to the betterment of society.

\section{Funding:}

This research received no funding.

\section{Conflicts of Interest:}

The author declares no conflict of interest. 


\section{References}

Anaeto, S.G., Onabajo, O.S., \& Osifeso, J. (2008). Models and theories of communication. African Renaissance Book Incorporated.

Asemah, E.S. (2009). Principles and practice of mass communication. Great Future Press

Bicen, H. \& Cavus, N. (2010). The most preferred social network sites by students. Procedia - Social and Behavioral Sciences, 2(2), 5864-5869. http://dx.doi.org/10.1016/j.sbspro.2010.03.958

Boes, S., Marti, J., \& Maclean, J. C. (2015). The impact of smoking bans on smoking and consumer behavior: Quasi-experimental evidence from Switzerland. Health Economics, 24(11), 1502-1516. https://doi.org/10.1002/hec.3108

Cornuz, J., Gilbert, A., Pinget, C., McDonald, P., Slama, K., Salto, E., \& Paccaud, F. (2006). Cost-effectiveness of pharmacotherapies for nicotine dependence in primary care settings: a multinational comparison. Tobacco Control, 15(3), 152-159. https://tobaccocontrol.bmj.com/content/15/3/152.short

Edegoh, L. O., Asemah, E. S., \& Ekanem, I. (2013). Facebook and relationship management among students of Anambra State University, Uli, Nigeria. International Review of Social Sciences and Humanities, 6(1), 205-216.

Eke, H. N., \& Odoh, N. J. (2014). The use of social networking sites among the undergraduate students of University of Nigeria, Nsukka. Library Philosophy and Practice, 0_1. http://citeseerx.ist.psu.edu/viewdoc/download?doi=10.1.1.677.2635\&rep=rep1\&type $=$ pdf

Francis, T. C., Chandra, R., Friend, D. M., Finkel, E., Dayrit, G., Miranda, J., ... \& Lobo, M. K. (2015). Nucleus accumbens medium spiny neuron subtypes mediate depressionrelated outcomes to social defeat stress. Biological Psychiatry, 77(3), 212-222. https://doi.org/10.1016/j.biopsych.2014.07.021

Gallion, A. J. (2010). Applying the uses and gratifications theory to social networking sites: A review of related literature. Indiana University. https://www.academia.edu/1077670/

Gallopel-Morvan, K., Gabriel, P., Le Gall-Ely, M., Rieunier, S., \& Urien, B. (2011). The use of visual warnings in social marketing: The case of tobacco. Journal of Business Research, 64(1), 7-11. https://doi.org/10.1016/j.jbusres.2009.09.012

Gharlipour, Z., Hazavehei, S. M. M., Moeini, B., Nazari, M., Beigi, A. M., Tavassoli, E., ... \& Barkati, H. (2015). The effect of preventive educational program in cigarette smoking: Extended Parallel Process Model. Journal of Education and Health Promotion, 4(4) https://dx.doi.org/10.4103\%2F2277-9531.151875

Gröppel-Klein, A. (2014). No motion without emotion: Getting started with hard facts on a soft topic. NIM Marketing Intelligence Review, 6(1), 8-15. https://sciendo.com/pdf/10.2478/gfkmir-2014-0002

Hagger, H., McIntyre, D., \& Wilkin, M. (Eds.). (2013). Mentoring: Perspectives on schoolbased teacher education. Routledge.

Hoogendoorn, B., Pennings, E., \& Thurik, R. (2010). What do we know about social entrepreneurship: An analysis of empirical research. https://papers.ssrn.com/sol3/papers.cfm?abstract_id=1462018

Hupp, O., Gröppel-Klein, A., Dieckmann, A., Broeckelmann, P., \& Walter, K. (2008). Beyond verbal scales: Measurement of emotions in advertising effectiveness research. Yearbook of Marketing and Consumer Research, 6(4), 72-99.

Johnston, L., Miech, R., O'Malley, P., Bachman, J., Schulenberg, J., \& Patrick, M. (2020). Demographic subgroup trends among adolescents in the use of various licit and illicit 
Prevalence of the Uses and Gratifications Theory amongst the university student consumers ...

drugs, 1975-2019. Monitoring the Future Occasional Paper No. 94. https://deepblue.lib.umich.edu/bitstream/handle/2027.42/162581/mtf-occ94.pdf

John, R. M., Sinha, P., Munish, V. G., \& Tullu, F. T. (2021). Economic Costs of Diseases and Deaths Attributable to Tobacco Use in India, 2017-2018. Nicotine and Tobacco Research, 23(2), 294-301. https://doi.org/10.1093/ntr/ntaa154

Kan, K. (2007). Cigarette smoking and self-control. Journal of Health Economics, 26(1), 6181. https://doi.org/10.1016/j.jhealeco.2006.07.002

Kaplan, A. and M. Haenlein. (2010). Users of the world, unite! The challenges and opportunities of social media. Business Horizons, 53(1), 59-68. http://dx.doi.org/10.1016/j.bushor.2009.09.003

Lewis, B. K. (2009). Social media and strategic communication: Attitudes and perceptions among college students. Doctoral Dissertation, Oklahoma State University).

Li, D. (2005). Why do you blog: A uses-and-gratifications inquiry into bloggers motivations http://citeseerx.ist.psu.edu/viewdoc./download?doi=10.1.1.91.6790 \&rep=rep1\&type $=$ pdf

Loewenstein, G. (1996). Out of control: Visceral influences on behavior. Organizational Behavior and Human Decision Processes, 65(3), 272-292. https://doi.org/10.1006/obhd.1996.0028

Matei, S. A. (2010). What can $U$ \& $G$ theory tell us about social media? http://matei.org/think/2010/07/29/what-can-uses-and-gratifications-theory-tellusabout-social-medial.

Marti, J., \& Sindelar, J. (2015). Smaller cigarette pack as a commitment to smoke less? Insights from behavioral economics. PLoS One, 10(9), e0137520. https://journals.plos.org/plosone/article?id=10.1371/journal.pone.0137520

McMaster, C., \& Lee, C. (1991). Cognitive dissonance in tobacco smokers. Addictive Behaviors, 16(5), 349-353. https://doi.org/10.1016/0306-4603(91)90028-g

McQuail, D. (2010). Mass communication theory $\left(6^{\text {th }}\right.$ Ed.). Sage Publications Ltd.

Osatuyi, B. (2013). Information sharing on social media sites. Computers in Human Behavior 29(6), 2622-2631. http://dx.doi.org/10.1016/j.chb.2013.07.001

Papoola, M. (2014). New media usage for communication and self-concept among journalism and mass communication students in Oyo State, Nigeria. New Media and Mass Communication 26(1), 22-34.

Park, K. I., \& Park, M. (2018). Fundamentals of probability and stochastic processes with applications to communications (pp. 51-72). Springer.

Peter, K. P., Mute, B. R., Doiphode, S. S., Bardapurkar, S. J., Borkar, M. S., \& Raje, D. V. (2013). Association between periodontal disease and chronic obstructive pulmonary disease: a reality or just a dogma? Journal of periodontology, 84(12), 1717-1723. https://doi.org/10.1902/jop.2013.120347

Peters Jr, R. J., Meshack, A., Lin, M. T., Hill, M., \& Abughosh, S. (2013). The social norms and beliefs of teenage male electronic cigarette use. Journal of ethnicity in substance abuse, 12(4), 300-307.

Rothschild, R. (1999). Cartel stability when costs are heterogeneous. International Journal of Industrial Organization, 17(5), 717-734. https://doi.org/10.1016/S01677187(97)00052-0

Strahan, E. J., White, K., Fong, G. T., Fabrigar, L. R., Zanna, M. P., \& Cameron, R. (2002). Enhancing the effectiveness of tobacco package warning labels: a social psychological perspective. Tobacco Control, 11(3), 183-190. https://doi.org/10.1136/tc.11.3.183 
U. Farooq

Vangeli, E., Stapleton, J., Sit, E. S., Borland, R., \& West, R. (2011). Predictors of attempts to stop smoking and their success in adult general population samples: a systematic review. Addiction, 106(12), 2110-2121.

Whiting, A. \& Williams. D. (2013). Why people use social media: a uses and gratifications approach. Qualitative Market Research: An International Journal 16(4), 362-369. http://dx.doi.org/10.1108/QMR-06-2013-0041

Whittingham, J., Ruiter, R. A., Zimbile, F., \& Kook, G. (2008). Experimental pretesting of public health campaigns: A case study. Journal of Health Communication, 13(3), 216229. https://doi.org/10.1080/10810730701854045

Wimmer, R. D. and J. R. Dominick. (2014). Mass media research: An introduction (10 ${ }^{\text {th }}$ Ed.). Wadsworth Cengage Learning.

Witter, K., \& Allen, M. (2000). A meta-analysis of fear appeals: Implications for effective public health campaigns. Health Education \& Behavior, 27(5), 591-615. https://doi.org/10.1177\%2F109019810002700506

You, S. J. and S. Kim. (2013). How and why college students use Web 2.0 applications: The role of social media in formal and informal learning. International Journal of Web Based Communities, 9(2), 174-187. http://dx.doi.org/10.1504/IJWBC. 2013.053242

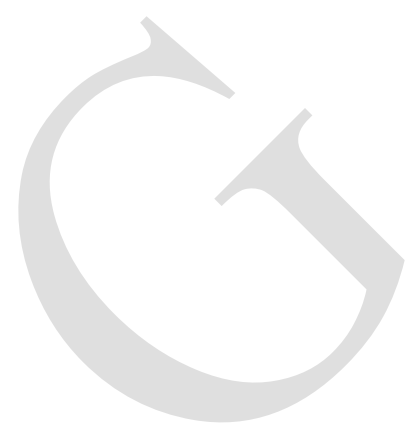

Journal of Humanities, Social and Management Sciences (JHSMS)

99 